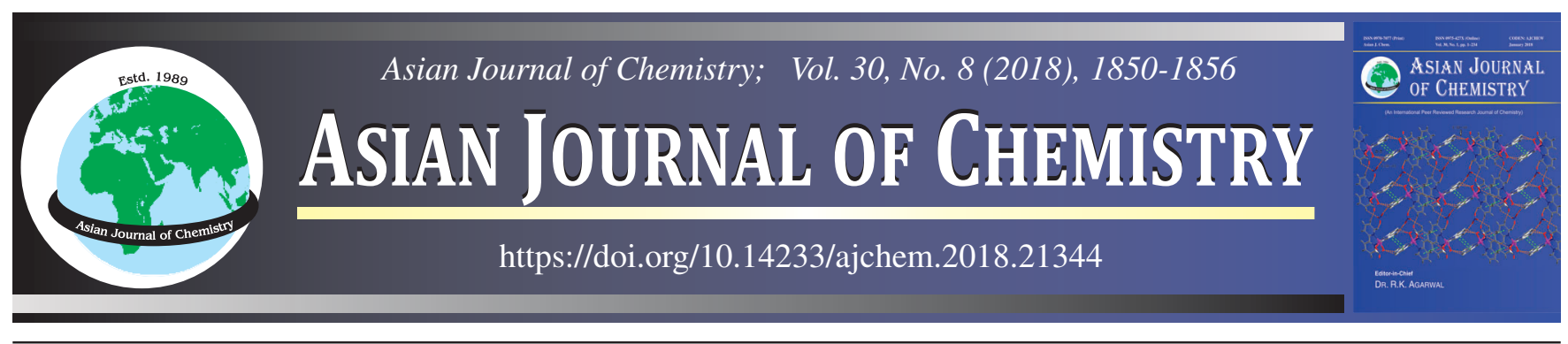

\title{
Inhibitive Effects of cis-2,6-Diphenyl-3-alkyl Piperidine at Aluminium/1 N Hydrochloric Acid Interface
}

\section{A. Ilamparithi ${ }^{1}$, S. Ponnuswamr ${ }^{2, *}$ and A. Selvaraj ${ }^{3}$}

${ }^{1}$ Department of Chemistry, Gobi Arts \& Science College (Autonomous), Gobichettipalayam-638 453, India

${ }^{2}$ Department of Chemistry, Government Arts College (Autonomous), Coimbatore-641 018, India

${ }^{3}$ Department of Chemistry, CBM College, Coimbatore-641 042, India

*Corresponding author: E-mail: kspons2001@gmail.com; ailamparithi@yahoo.com

Three piperidine molecules viz., $t$-3-methyl- $r$-2,c-6-diphenylpiperidine (3MP), $t$-3-ethyl- $r$-2,c-6-diphenylpiperidine (3EP), $t$-3,c-5-dimethyl$r$-2,c-6-diphenylpiperidine (DMP) were treated in different concentrations to decide their capability to inhibit the dissolution of aluminium in $1 \mathrm{~N} \mathrm{HCl}$. Gravimetric method, AC impedance (EIS) and potentiodynamic polarization techniques were employed to ascertain the corrosion of aluminium. The weight loss is found to be concentration and temperature dependent. The effect of temperature (303-333 K) was examined to find out the thermodynamic parameters like $\Delta \mathrm{H}^{\#}, \Delta \mathrm{S}^{\#}$ and $\Delta \mathrm{G}_{\text {ads }}^{\mathrm{o}}$ and activation parameter $\mathrm{E}_{\mathrm{a}}$. Polarization data revealed that the piperidine inhibitor molecules were mixed type. By using Nyquist plots the double layer capacitance and charge transfer resistance values were obtained. The impedance data proved the adsorption of inhibitor molecules on the aluminium surface. Surface coverage ( $\theta$ ) parameter was found to fit Tempkin adsorption isotherm. Scanning electron microscopy and energy dispersive X-ray spectroscopy (EDS) were utilized to investigate the aluminium surface.

Keywords: EIS, Nyquist plots, Tafel plots, SEM, EDS.

\section{INTRODUCTION}

Aluminium and its alloys have low density, corrosion resistance and low cost. The formation of aluminium oxide layer naturally on its surface is responsible for corrosion resistance of aluminium and its alloys. Acids are normally employed for industrial cleaning. However, in $\mathrm{HCl}$ and $\mathrm{H}_{2} \mathrm{SO}_{4}$ the oxide film is susceptible to corrosion [1,2]. For arresting the corrosion in acidic medium, organic inhibitor molecules possessing atoms like $\mathrm{N}, \mathrm{O}, \mathrm{S}$ and $\mathrm{P}$ play a crucial role in industries [3,4]. Adsorption of piperidine inhibitor molecules on the aluminium surface is the foremost mechanism of action in its inhibitive role. The method of adsorption of inhibitor molecules are controlled by the charge, nature on the metal surface and the chemical structure of inhibitors. Generally, the tendency to form a stronger coordination bond by the lone pair of electrons in hetero-atoms with the metal surface decides its inhibition efficiency and hence inhibitive efficiency following the order: $\mathrm{O}<\mathrm{N}<\mathrm{S}<\mathrm{P}$ [5]. The objective of the present work is to investigate the inhibitive efficiency of three cis-2,6-diphenylpiperidines on the corrosion of aluminium in $1 \mathrm{~N} \mathrm{HCl}$.

\section{EXPERIMENTAL}

Synthesis of the inhibitors: cis-2,6-Diphenylpiperidin4-ones were reduced by Wolff-Kishner reduction method for the synthesis of cis-2,6-diphenylpiperidines [6-9] and their structures are depicted in Fig. 1.

Hydrochloric acid (AR grade) from Merck and double distilled water were used for the preparation of $1 \mathrm{~N} \mathrm{HCl}$ solution. The samples were rectangular plates of aluminium alloy measuring $3 \mathrm{~cm} \times 1 \mathrm{~cm} \times 0.1 \mathrm{~cm}$ and the composition of the sample is $99 \% \mathrm{Al}$.

Weight loss studies: The wet silicon carbide emery paper of $100,200,400,600$ and 800 grades were used to polish the samples to mirror finish. The samples were washed with double distilled water and degreased in tricholoroethene. Three rectangular aluminum plates were immersed in $100 \mathrm{~mL}$ of uninhibited and inhibited solution of $1 \mathrm{~N} \mathrm{HCl}$ for $1 \mathrm{~h}$. As described in the literature, the rate of corrosion $(\mathrm{mm} / \mathrm{Y})$, inhibition efficiency and surface coverage $(\theta)$ were determined from weight loss values of uninhibited and inhibited solution of $1 \mathrm{~N} \mathrm{HCl}$. The weight loss and inhibition efficiency were determined at four different temperatures viz., 303, 313, 323 and $333 \mathrm{~K}$. 
<smiles>CC1CCC(c2ccccc2)NC1c1ccccc1</smiles>

(A)

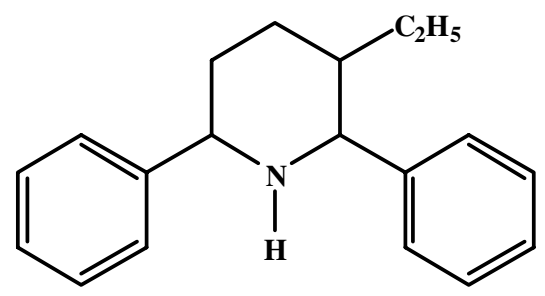

(B)

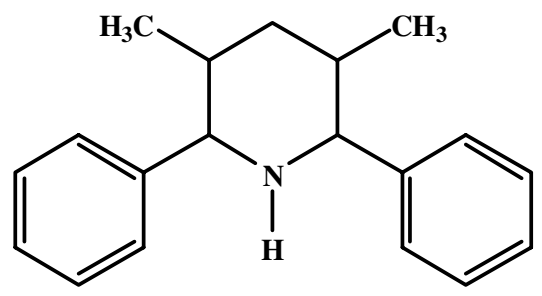

(C)

Fig. 1 Chemical structure of piperidines (A) $t$-3-methyl-r-2,c-6-diphenyl-piperidine (3MP), $t$-3-ethyl- $r$-2,c-6-diphenylpiperidine (3EP), $t$-3,c5-dimethyl-r-2,c-6-diphenylpiperidine (DMP)

Electrochemical analysis: The conventional three cell electrode assembly was used for EIS. The working electrode used was the same aluminium sample implanted in Teflon with an uncovered area of $1 \mathrm{~cm}^{2}$. The saturated calomel electrode and platinum electrode were employed as a reference and Auxiliary electrodes, respectively. Potentiodynamic polarization studies and electrochemical impedance measurements were carried out at the open circuit potential using Potentiostat/ Galvanostat/FRA2 ( $\mu$ Autolab type 3 ) under laboratory air condition. Potentiodynamic polarization curves were measured from $+200 \mathrm{mV}$ to $-200 \mathrm{mV}$ with a sweep rate of $1 \mathrm{mV} \mathrm{s}^{-1}$ with respect to the corrosion potential. Tafel extrapolation method was employed to determine $\mathrm{E}_{\text {corr }}$ and $\mathrm{I}_{\text {corr }}$ values. Before measuring potentiodynamic polarization, electrochemical impedance values were obtained at $30 \pm 1{ }^{\circ} \mathrm{C}$ and at open circuit potential. Ivium frequency response analyzer with a signal amplitude perturbation of $10 \mathrm{mV}$ was used to get the superimposed sine wave AC signal. Altering the frequency range from $100 \mathrm{KHz}$ to. $01 \mathrm{~Hz}$, the impedance spectra were measured.

\section{RESULTS AND DISCUSSION}

Gravimetric measurements: The weight loss, corrosion rate and inhibition efficiency of $t$-3-methyl- $r$-2,c-6-diphenylpiperidine (3MP), $t$-3-ethyl- $r$-2,c-6-diphenylpiperidine (3EP), $t$-3,c-5-dimethyl-r-2,c-6-diphenylpiperidine (DMP) with various concentrations on aluminium surface in $1 \mathrm{~N} \mathrm{HCl}$ are listed in Table-1. The inhibition efficiency raises with increase in concentration of the inhibitor and reaches a maximum at $5 \mathrm{mM}$ for all the inhibitors. The inhibitor efficiency follows the order 3EP $>3 \mathrm{MP}>\mathrm{DMP}$ in $1 \mathrm{~N} \mathrm{HCl}$. The same trend was proposed by Mahmoud [3] for piperidines on zinc alloy. We have obtained the same order for $N$-formyl piperidin-4-ones [4]. This may be due to the electron releasing nature $(+\mathrm{I}$ effect) of alkyl groups. The electron releasing ability raises with increase in chain length of alkyl groups and hence the ethyl group shows more efficiency than methyl group. When inhibitor molecules are present in large numbers it increases the probability of adsorption on the metal surface, leading to the increased inhibition efficiency [10].

Electrochemical impedance: The typical Nyquist plots of aluminium in inhibited and uninhibited acid solution containing a range of concentrations of $3 \mathrm{MP}, 3 \mathrm{EP}$ and DMP are shown in Figs. 2-4. It is evident from Table-2 that the $R_{c t}$ value and inhibition efficiency increases with the raise in the concentrations of piperidine molecules. Diffusion process and activation process are known methods of inhibition by organic molecules. Usually, Nyquist plots obtained for a semi-circular loop for the activation controlled inhibition process and a linear

\begin{tabular}{|c|c|c|c|c|}
\hline \multicolumn{5}{|c|}{$\begin{array}{c}\text { TABLE-1 } \\
\text { GRAVIMETRIC PARAMETERS FOR VARIOUS } \\
\text { CONCENTRATION OF PIPERDINES }\end{array}$} \\
\hline \multirow[b]{2}{*}{ Inhibitor } & \multirow[b]{2}{*}{$\begin{array}{l}\text { Conc. } \\
(\mathrm{mM})\end{array}$} & \multicolumn{3}{|c|}{$\mathrm{HCl}$} \\
\hline & & $\begin{array}{l}\text { Weight } \\
\text { loss }(g)\end{array}$ & $\begin{array}{l}\text { Corrosion rate } \\
(\mathrm{mm} / \mathrm{y}) \times 100\end{array}$ & $\mathrm{IE}(\%)$ \\
\hline & Blank & 0.2847 & 30.79 & - \\
\hline \multirow{4}{*}{$3 \mathrm{MP}$} & 0.1 & 0.2483 & 26.85 & 12.79 \\
\hline & 1.0 & 0.1832 & 19.81 & 35.65 \\
\hline & 3.0 & 0.1433 & 15.50 & 49.70 \\
\hline & 5.0 & 0.1394 & 15.07 & 51.04 \\
\hline \multirow{4}{*}{$3 \mathrm{EP}$} & 0.1 & 0.2419 & 26.16 & 15.03 \\
\hline & 1.0 & 0.1784 & 19.29 & 37.34 \\
\hline & 3.0 & 0.1405 & 15.19 & 50.65 \\
\hline & 5.0 & 0.1302 & 14.08 & 54.27 \\
\hline \multirow{4}{*}{ DMP } & 0.1 & 0.2513 & 27.16 & 11.73 \\
\hline & 1.0 & 0.2182 & 23.60 & 23.36 \\
\hline & 3.0 & 0.1939 & 20.97 & 31.89 \\
\hline & 5.0 & 0.1785 & 19.30 & 37.30 \\
\hline
\end{tabular}

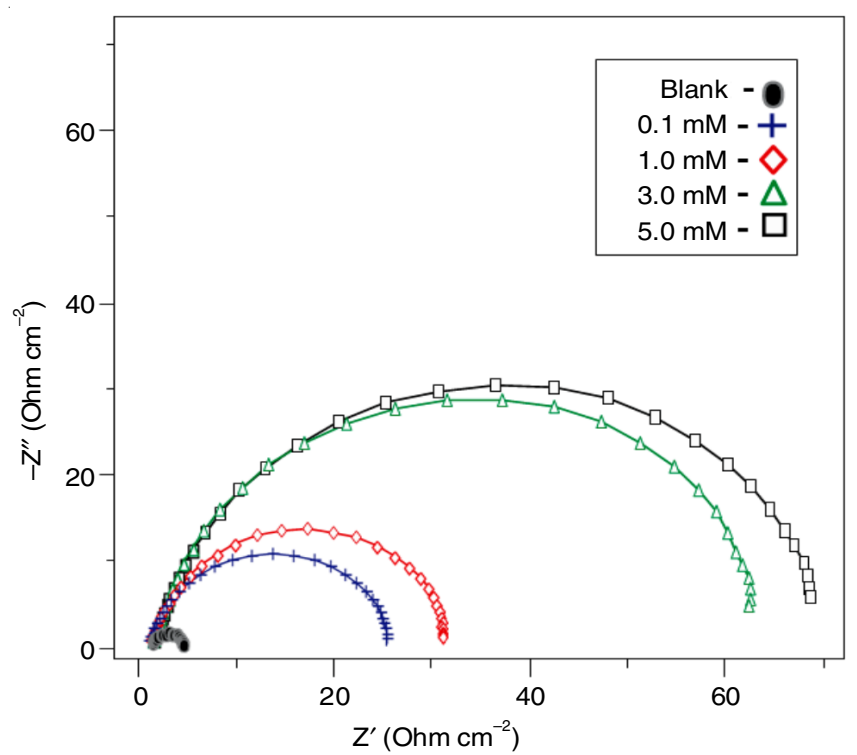

Fig. 2. Nyquist representation for $\mathrm{Al}$ in $1 \mathrm{~N} \mathrm{HCl}$ in the absence and presence of $3 \mathrm{MP}$

pattern for a diffusion controlled inhibition process. Since all the inhibitor molecules shows semi-circular loops in their Nyquist curves, the inhibition by piperidine molecules on aluminium surface is activation controlled.

Fig. 5 shows the Randles equivalent circuit used for the impedance analysis. These circuits fall into the classical parallel resistor capacitor combination, the acid solution dissolved with inhibitor molecule acts as a series resistor. 


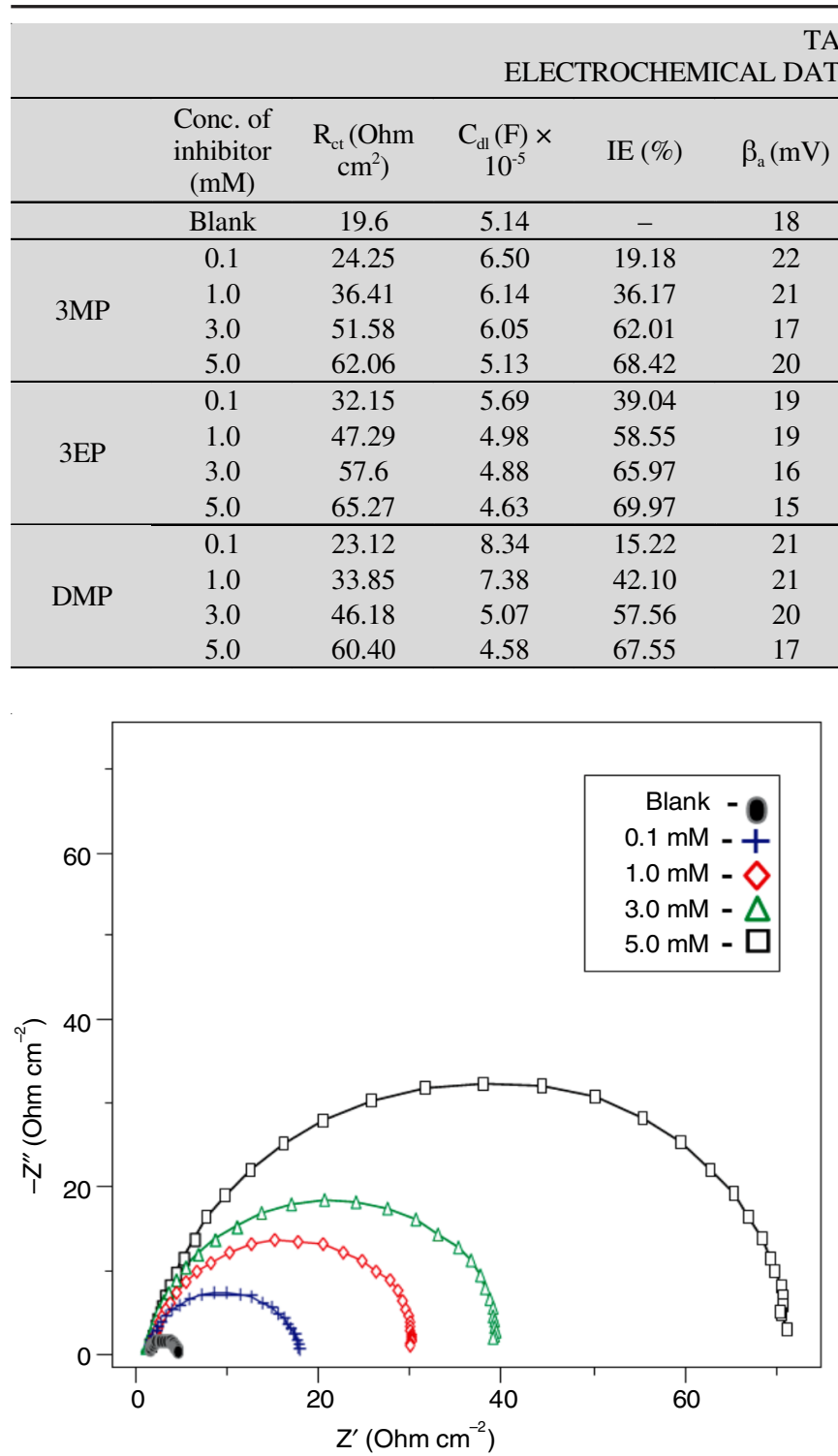

Fig. 3. Nyquist representation for $\mathrm{Al}$ in $1 \mathrm{~N} \mathrm{HCl}$ in the absence and in the presence of 3EP

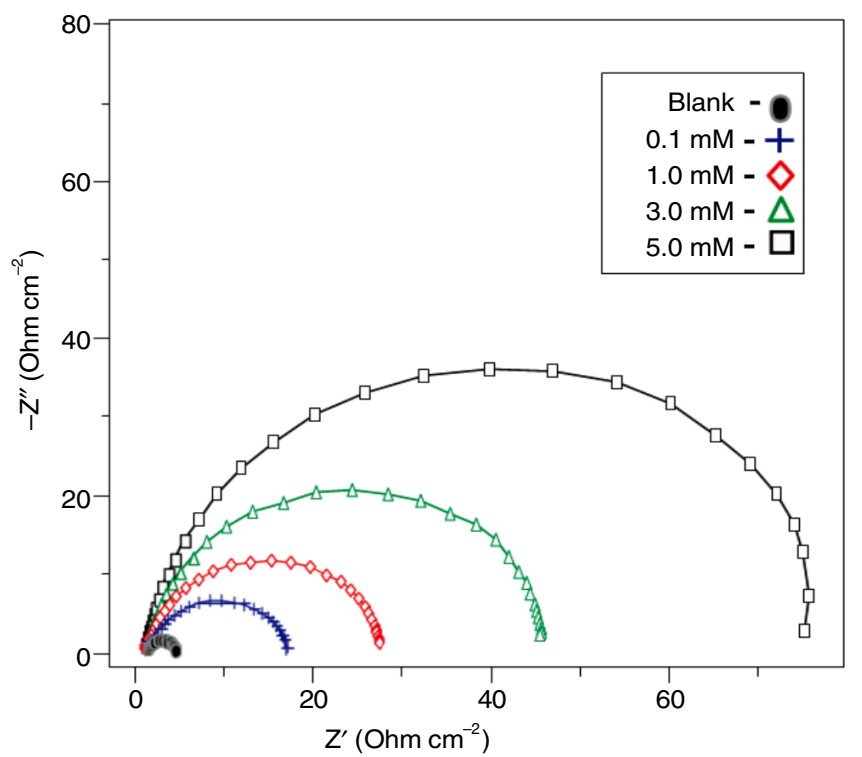

Fig. 4. Nyquist representation for $\mathrm{Al}$ in $1 \mathrm{~N} \mathrm{HCl}$ in the absence and in the presence of DMP

TABLE-2

DATA OF ALUMINIUM IN $1 \mathrm{~N} \mathrm{HCl}$

\begin{tabular}{ccccccccccc}
$\begin{array}{c}\text { onc. of } \\
\text { hibitor } \\
(\mathrm{mM})\end{array}$ & $\begin{array}{c}\mathrm{R}_{\mathrm{ct}}(\mathrm{Ohm} \\
\left.\mathrm{cm}^{2}\right)\end{array}$ & $\begin{array}{c}\mathrm{C}_{\mathrm{dl}}(\mathrm{F}) \times \\
10^{-5}\end{array}$ & $\mathrm{IE}(\%)$ & $\beta_{\mathrm{a}}(\mathrm{mV})$ & $\beta_{\mathrm{c}}(\mathrm{mV})$ & $\begin{array}{c}\mathrm{I}_{\text {corr }} \\
\left(\mu \mathrm{A} / \mathrm{cm}^{2}\right)\end{array}$ & $\begin{array}{c}-\mathrm{E}_{\text {corr }} \\
(\mathrm{mV})\end{array}$ & $\begin{array}{c}\text { Corrosion } \\
\text { rate } \\
(\mathrm{mm} / \mathrm{y})\end{array}$ & $\begin{array}{c}\mathrm{R}_{\mathrm{p}} \\
(\mathrm{Ohm})\end{array}$ & $\begin{array}{l}\mathrm{IE}(\%) \\
\text { Blank }\end{array}$ \\
\hline 19.6 & 5.14 & - & 18 & 104 & 982.5 & 776.9 & 14.93 & 8.556 & - \\
\hline 0.1 & 24.25 & 6.50 & 19.18 & 22 & 113 & 743.8 & 801.9 & 11.3 & 11.13 & 24.30 \\
1.0 & 36.41 & 6.14 & 36.17 & 21 & 108 & 519.3 & 800.9 & 7.892 & 18.17 & 47.15 \\
3.0 & 51.58 & 6.05 & 62.01 & 17 & 89 & 347.9 & 793 & 3.96 & 27.09 & 64.59 \\
5.0 & 62.06 & 5.13 & 68.42 & 20 & 74 & 196.2 & 787.5 & 2.982 & 44.09 & 80.03 \\
\hline 0.1 & 32.15 & 5.69 & 39.04 & 19 & 90 & 619 & 800.1 & 8.6 & 16.65 & 37.00 \\
1.0 & 47.29 & 4.98 & 58.55 & 19 & 87 & 427.4 & 796.1 & 6.496 & 18.92 & 56.5 \\
3.0 & 57.6 & 4.88 & 65.97 & 16 & 85 & 260.5 & 794.5 & 5.297 & 37.01 & 73.49 \\
5.0 & 65.27 & 4.63 & 69.97 & 15 & 87 & 185.2 & 784.7 & 2.815 & 43.42 & 81.15 \\
\hline 0.1 & 23.12 & 8.34 & 15.22 & 21 & 119 & 846.4 & 799 & 14.38 & 10.67 & 13.85 \\
1.0 & 33.85 & 7.38 & 42.10 & 21 & 105 & 673.4 & 791.3 & 10.23 & 14.41 & 31.46 \\
3.0 & 46.18 & 5.07 & 57.56 & 20 & 102 & 458.2 & 789.6 & 6.964 & 20.14 & 53.36 \\
5.0 & 60.40 & 4.58 & 67.55 & 17 & 94 & 361.5 & 785 & 5.494 & 22.35 & 63.21 \\
\hline
\end{tabular}

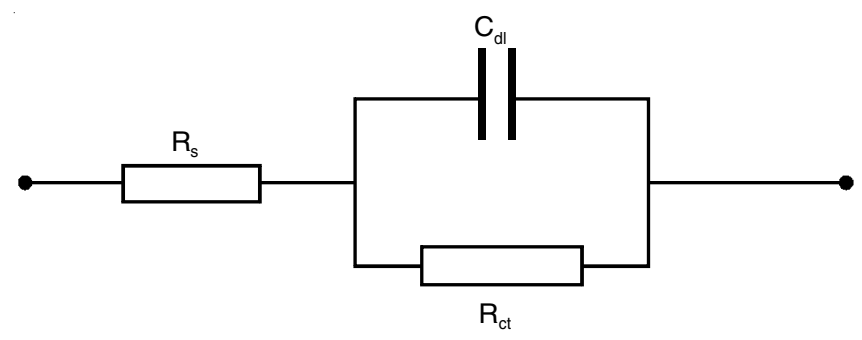

Fig. 5. Randles equivalent circuit

The inhibitor efficiency of all the inhibitor molecules raises with increase in concentration of the inhibitor molecules and which is similar to weight loss method. From the Figs. 2-4, it is suggested that with increase in concentration of piperidine molecules the radius of semi-circle, $R_{\mathrm{ct}} / 2$ and hence $\mathrm{R}_{\mathrm{ct}}$ will increases. With progress in adsorption of inhibitor molecule (with low dielectric constant) replaces water molecule on the surface of the metal (with high dielectric constant). This lead to decrease in double layer capacitance $\mathrm{C}_{\mathrm{dl}}$. Moreover, with increase in adsorption of the piperidine molecule on the metal surface increases the thickness of the electrical double layer which causes the decreases of $\mathrm{C}_{\mathrm{dl}}$ values $[11,12]$.

Polarization measurements: The polarization curves for aluminium in $1 \mathrm{~N}$ hydrochloric acid solution in the presence and absence of inhibitors are shown in Figs. 6-8. Since the addition of inhibitor molecules to the acid medium alters both the cathodic and anodic Tafel slopes, hence the inhibitors are mixed type. However, the cathodic polarization curves are altered much more than anodic polarization curves and hence they are slightly more cathodic in nature. The corrosion potential $\left(\mathrm{E}_{\text {corr }}\right)$, corrosion current density $\left(\mathrm{I}_{\text {corr }}\right)$, cathodic and anodic slopes $\left(\beta_{\mathrm{c}}\right.$ and $\beta_{\mathrm{a}}$ ), the inhibitor efficiency (IE \%) are shown in Table-2. The $\mathrm{E}_{\text {corr }}$ value has a small shift towards the active side with the raises in the inhibitor concentration. Hence, the $\mathrm{Al}$ dissolution reaction is controlled, without change in the corrosion mechanism. The blank solution has higher $\mathrm{I}_{\text {corr }}$ value than the inhibited solution. Adsorption of the piperidine molecules on the metal surface decreases the rate of cathodic hydrogen evolution reaction and anodic metal dissolution.

Effect of temperature: Corrosion rate (CR) and inhibitor efficiency (IE) at 303, 313, 323 and $333 \mathrm{~K}$ in presence of $1 \mathrm{mM}$ 


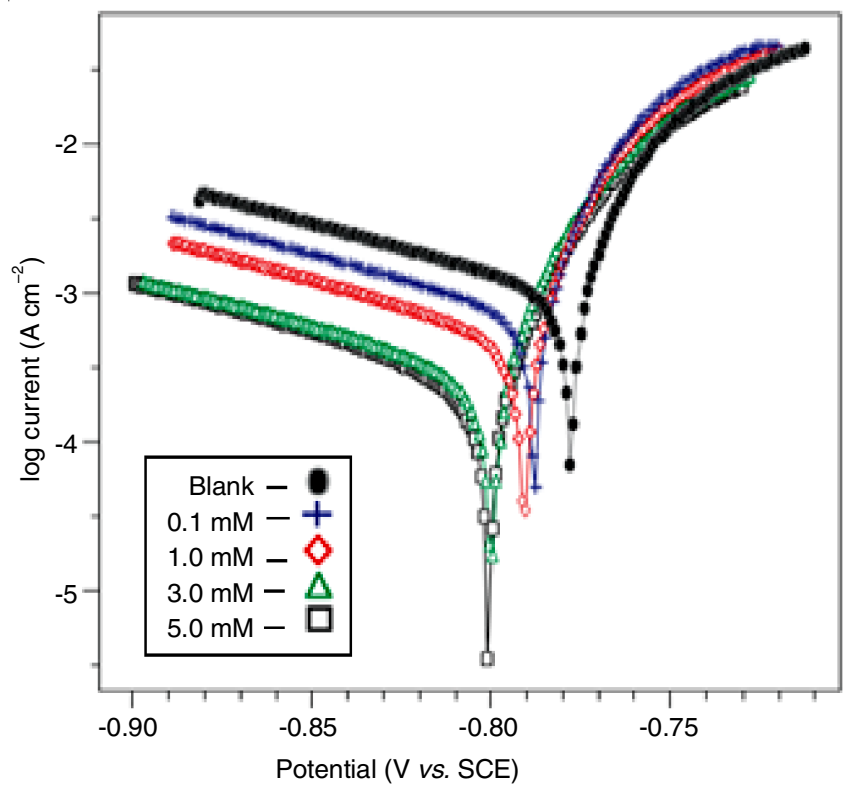

Fig. 6. Tafel polarization curves for $\mathrm{Al}$ in $1 \mathrm{~N} \mathrm{HCl}$ with various concentration of 3MP

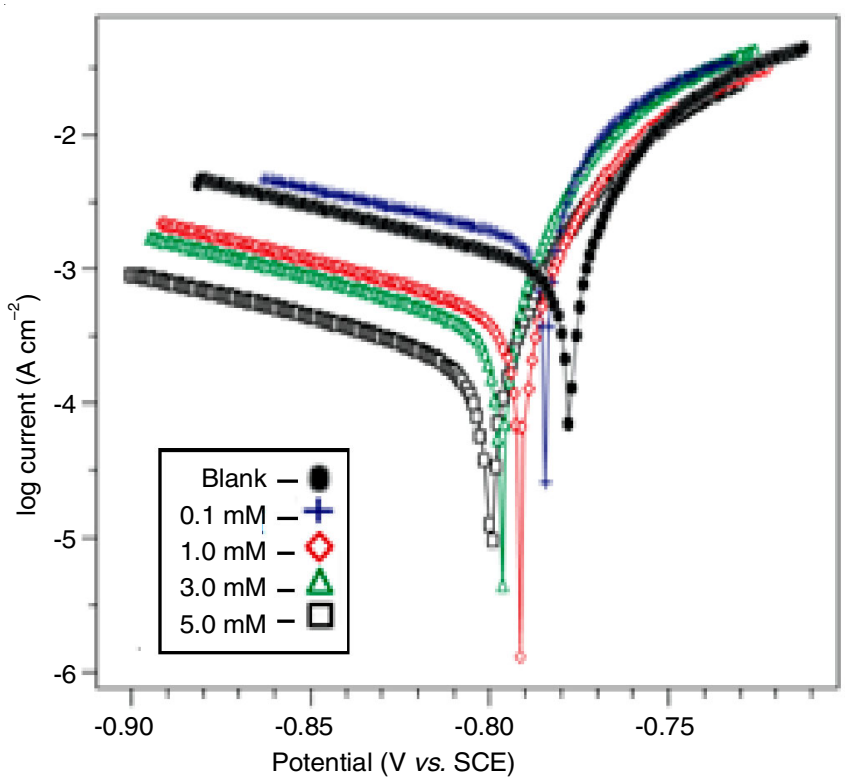

Fig. 7. Tafel polarization curves for $\mathrm{Al}$ in $1 \mathrm{~N} \mathrm{HCl}$ with various concentration of 3EP

inhibitors concentration are given in Table-3, which shows that the inhibitor efficiency increases with rise in temperature up to $333 \mathrm{~K}$

The thermodynamic parameters $\mathrm{E}_{\mathrm{a}}, \Delta \mathrm{H}^{\#}$ and $\Delta \mathrm{S}^{\#}$ are deduced from Arrhenius equation (1) and transition state equation (2). Fig. 9 depicts a plot $\log \mathrm{CR} v s . \mathrm{T}^{-1}$, which give a straight line with a negative slope equal to $\mathrm{E}_{\mathrm{a}} / 2.303 \mathrm{R}$. The values of $\Delta \mathrm{S}^{\#}$

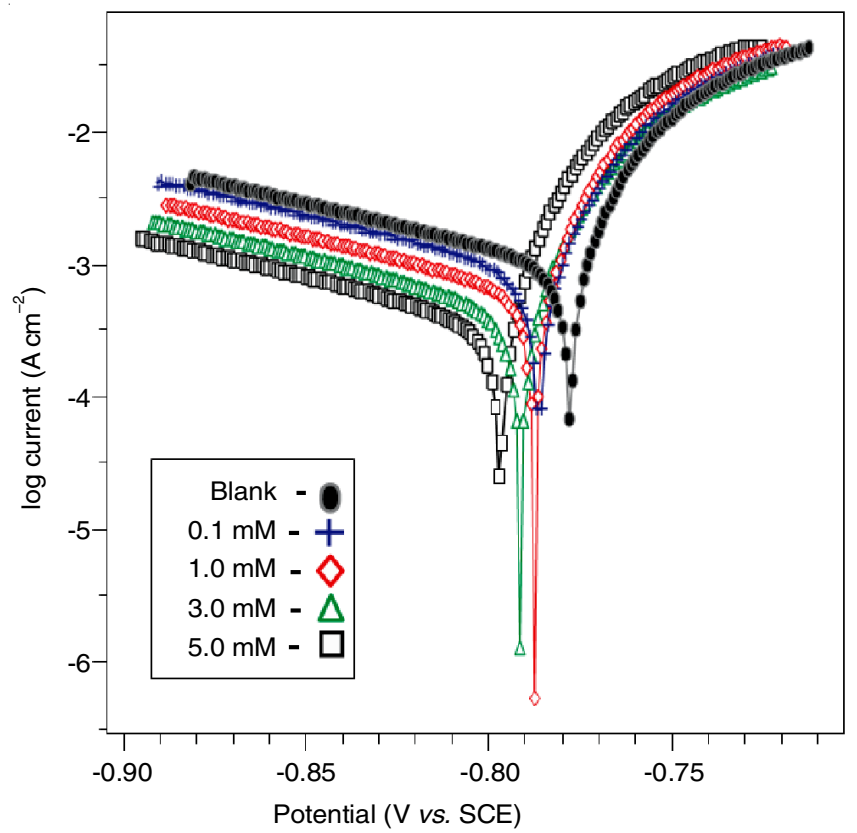

Fig. 8. Tafel polarization curves for $\mathrm{Al}$ in $1 \mathrm{~N} \mathrm{HCl}$ with various concentration of DMP

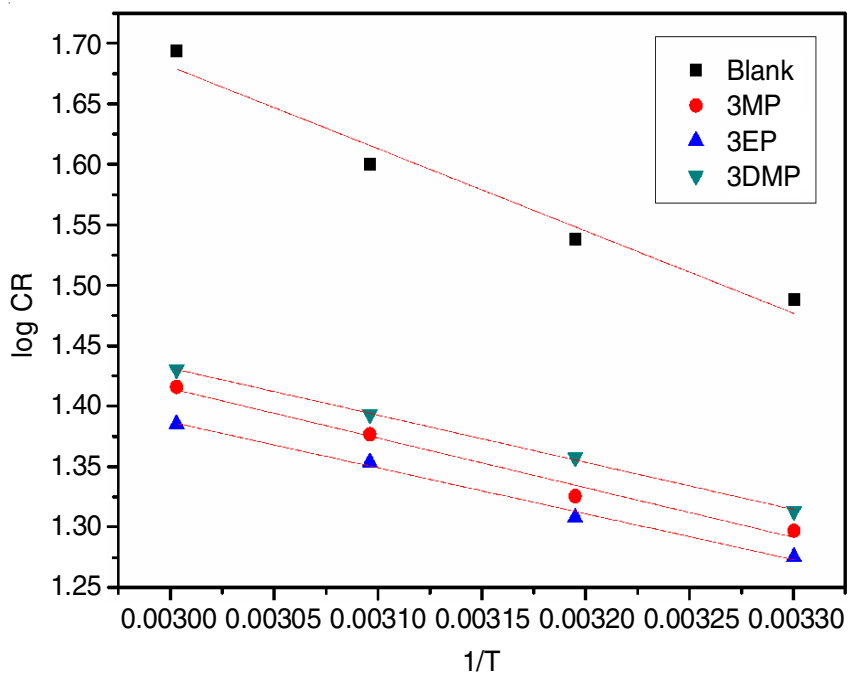

Fig. 9. Arrhenius plot of $\mathrm{Al}$ corrosion in $1 \mathrm{~N} \mathrm{HCl}$

and $\Delta \mathrm{H}^{\#}$ are calculated by a plot of $\log (\mathrm{CR} / \mathrm{T})$ versus $1 / \mathrm{T}$ with a slope of $\left(-\Delta \mathrm{H}^{\#} / 2.303 \mathrm{R}\right)$ and an intercept of $\left(\log \mathrm{R} / \mathrm{Nh}+\Delta \mathrm{S}^{\#} /\right.$ 2.303R).

$$
\begin{gathered}
\mathrm{k}=\mathrm{A} \exp \left(\frac{-\mathrm{E}_{\mathrm{a}}}{\mathrm{RT}}\right) \\
\mathrm{k}=\frac{\mathrm{RT}}{\mathrm{Nh}} \exp \left(\frac{\Delta \mathrm{S}^{\#}}{\mathrm{R}}\right) \exp \left(\frac{-\Delta \mathrm{H}^{\#}}{\mathrm{RT}}\right)
\end{gathered}
$$

TABLE-3

EFFECT OF TEMPERATURE ON ALUMINIUM CORROSION INHIBITION IN HCl-MEDIUM

\begin{tabular}{ccc|cc|cc|cc}
\hline \multirow{2}{*}{ System } & \multicolumn{2}{c|}{$303 \mathrm{~K}$} & \multicolumn{2}{c|}{$313 \mathrm{~K}$} & \multicolumn{2}{c|}{$323 \mathrm{~K}$} & \multicolumn{2}{c}{$333 \mathrm{~K}$} \\
\cline { 2 - 8 } & CR $(\mathrm{mm} / \mathrm{y})$ & IE $(\%)$ & CR $(\mathrm{mm} / \mathrm{y})$ & IE $(\%)$ & CR $(\mathrm{mm} / \mathrm{y})$ & IE $(\%)$ & CR $(\mathrm{mm} / \mathrm{y})$ & IE $(\%)$ \\
\hline Blank & 30.79 & & 34.50 & & 39.81 & & 49.37 \\
3MP & 19.81 & 35.65 & 21.15 & 38.68 & 23.80 & 40.21 & 26.04 \\
3EP & 18.85 & 38.78 & 20.31 & 41.13 & 22.58 & 43.28 & 24.29 \\
DMP & 20.57 & 33.19 & 22.78 & 33.95 & 24.74 & 37.90 & 26.93 & 47.25 \\
\hline
\end{tabular}




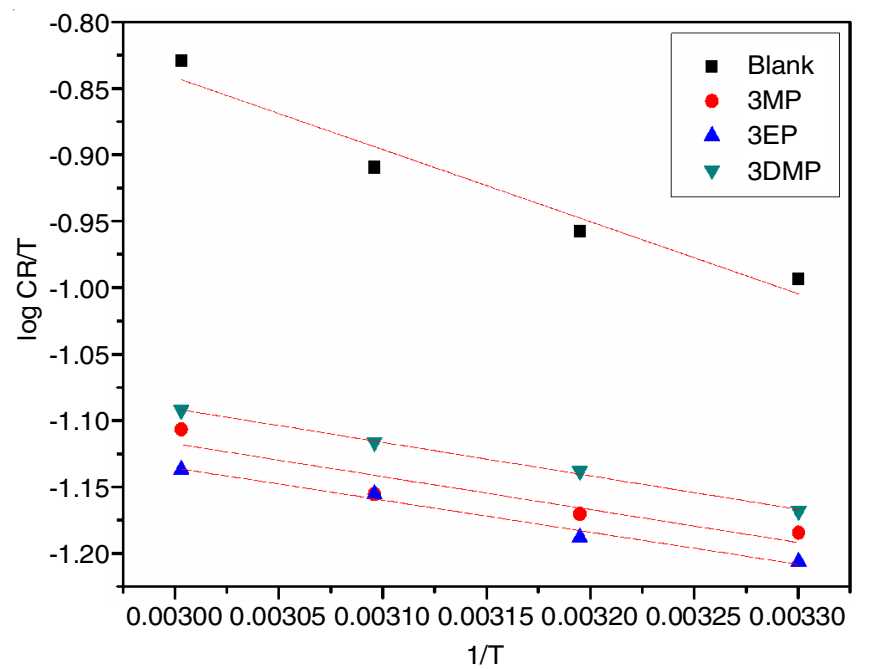

Fig. 10. Kinetic plot of $\mathrm{Al}$ corrosion in $1 \mathrm{~N} \mathrm{HCl}$

Table-4 indicates that the blank solution has higher activation energy than the inhibited solution. With raise in concentration of the inhibitors, the energy barrier for the corrosion process decreases. The positive sign of $\Delta \mathrm{H}^{\#}$ indicates that the exothermic nature of the corrosion inhibition reaction. The entropy of activation $\left(\Delta \mathrm{S}^{\#}\right)$, in the presence of inhibitor is more negative than the blank, which means that the activated complex in the rate determining step denotes association rather than dissociation.

\begin{tabular}{cccc}
\multicolumn{4}{c}{ TABLE-4 } \\
THERMODYNAMIC PARAMETERS \\
\hline Inhibitor & $\mathrm{E}_{\mathrm{a}}\left(\mathrm{kJ} \mathrm{mol}^{-1}\right)$ & $\Delta \mathrm{H}^{*}\left(\mathrm{~kJ} \mathrm{~mol}^{-1}\right)$ & $\Delta \mathrm{S}^{*}\left(\mathrm{~J} \mathrm{~K}^{-1} \mathrm{~mol}^{-1}\right)$ \\
\hline Blank & 13.024 & 10.388 & -182.52 \\
3MP & 7.859 & 4.747 & -204.72 \\
3EP & 7.263 & 4.628 & -205.43 \\
DMP & 7.471 & 4.832 & -203.96 \\
\hline
\end{tabular}

$\Delta \mathrm{G}^{\mathrm{o}}$ ads values are obtained for various temperatures from the expression $\Delta \mathrm{G}_{\text {ads }}^{\mathrm{o}}=-\mathrm{RT} \ln (55.5 \times \mathrm{K})$, (where the equilibrium constant $\mathrm{K}$ is equal to $[\theta /(1-\theta) \mathrm{C}]$ are presented in Table5. The strong interaction and spontaneous adsorption of the piperidine molecules on the aluminium surface are confirmed by the negative values of $\Delta \mathrm{G}^{\circ}{ }_{\text {ads }}$ and positive value of $\Delta \mathrm{H}^{\#}$ $[13,14]$. The low values of the $\Delta \mathrm{H}^{\#}$ indicate the formation of weak van der Waals bond between the inhibitor molecules and the aluminium surface through electrostatic attraction $[15,16]$.

TABLE-5

GIBBS FREE ENERGY OF ADSORPTION $\Delta \mathrm{G}_{\text {ads }}^{\circ}\left(\mathrm{kJ} \mathrm{mol}^{-1}\right)$

\begin{tabular}{ccccc}
\hline Inhibitor & $303 \mathrm{~K}$ & $313 \mathrm{~K}$ & $323 \mathrm{~K}$ & $333 \mathrm{~K}$ \\
\hline 3MP & -8.6329 & -9.2557 & -9.7235 & -10.8183 \\
3EP & -8.9706 & -9.5217 & -10.0628 & -11.2119 \\
DMP & -8.3582 & -8.7228 & -9.4628 & -10.6178 \\
\hline
\end{tabular}

Surface analysis: SEM pictures of virgin aluminium surface in Fig. 11(D,E) specify that the surface of the
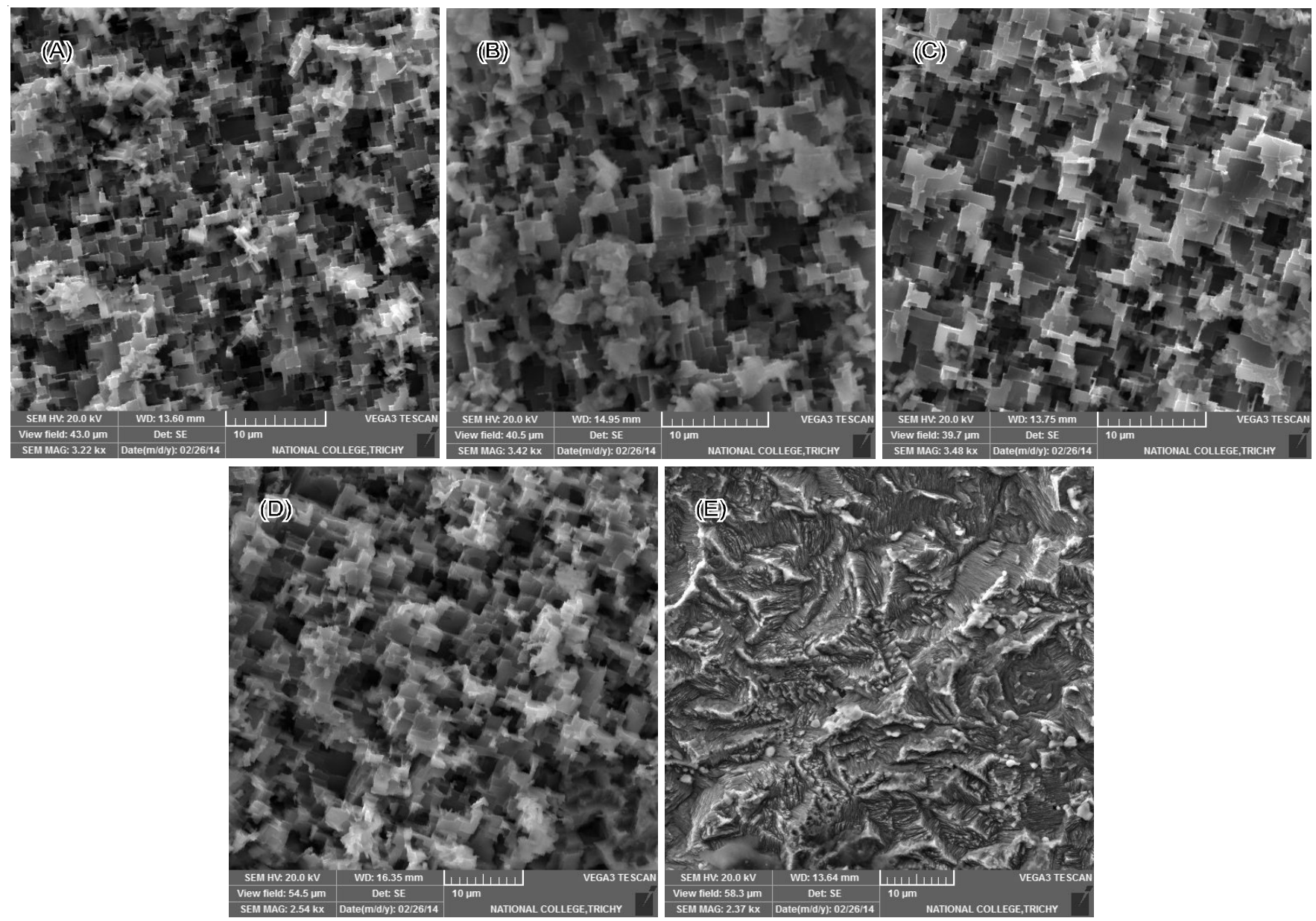

Fig. 11. SEM pictures of uninhibited $\mathrm{Al}$ (D and E) and Al surface inhibited by (A) 3MP, (B) 3EP and (C) DMP 

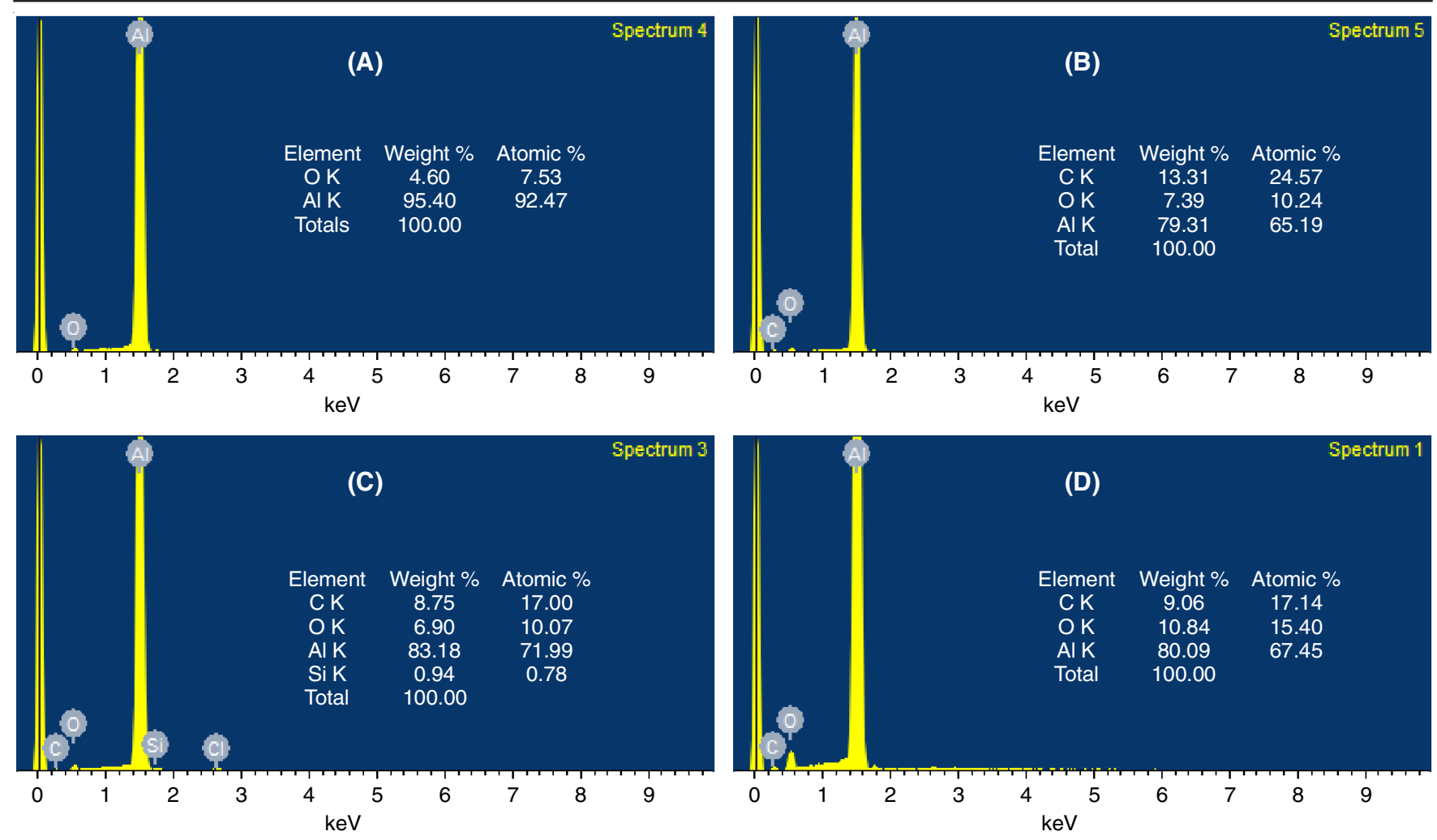

Fig. 12. EDS images of virgin $\mathrm{Al}$ surface (A) and $\mathrm{Al}$ surface adsorbed by $3 \mathrm{MP}(\mathrm{B}), 3 \mathrm{EP}(\mathrm{C})$ and $\mathrm{DMP}(\mathrm{D})$

aluminium is covered with hexagonal type aluminium oxide protective layer with small void surface. These gaps are penetrated by $\mathrm{Cl}^{-}$ions and the corrosion product molecules are dispersed. The SEM images of inhibited surface in Fig. $11(\mathrm{~A}, \mathrm{~B}, \mathrm{C})$ show that the inhibitors are uniformly adsorbed on the aluminium surface thus exhibiting protective action. By comparing the uninhibited EDS in Fig. 12(A) with inhibited EDS in Fig. 12(B,C,D) it can be derived that the weight percentage of $\mathrm{Al}$ has decreased and the weight percentage of carbon has increased, which clearly protrays the adsorption of inhibitors on the metal surface.

Adsorption isotherm: From gravimetric measurements, the degree of surface coverage $(\theta)$ for various inhibitor concentrations in $1 \mathrm{~N} \mathrm{HCl}$ was calculated. The data were tested graphically by fitting the surface coverage values into a suitable adsorption isotherm. Fig. 13 shows that, the adsorption data in this system fits well with Temkin isotherm. This may be due to the formation of mono layer and they form a barrier and thus preventing the metal from reacting with the ions of the aggressive media.

\section{Conclusion}

The cis-2,6-diphenylpiperidines were found to perform as efficient inhibitors for aluminium surface. The inhibition efficiency increases with the increase in the concentration of the inhibitor molecules. An optimum inhibitor concentration of $5 \mathrm{mM}$ has maximum percentage inhibition efficiency. The inhibition efficiency is affected by raise in temperature and it increases up to $333 \mathrm{~K}$. Polarization data showed that these inhibitors are mixed type inhibitors. EIS studies exposed that when the concentration of the inhibitor is moved up, the IE \% and $\mathrm{R}_{\mathrm{ct}}$ values tend to increases but $\mathrm{C}_{\mathrm{dl}}$ value decreases. The

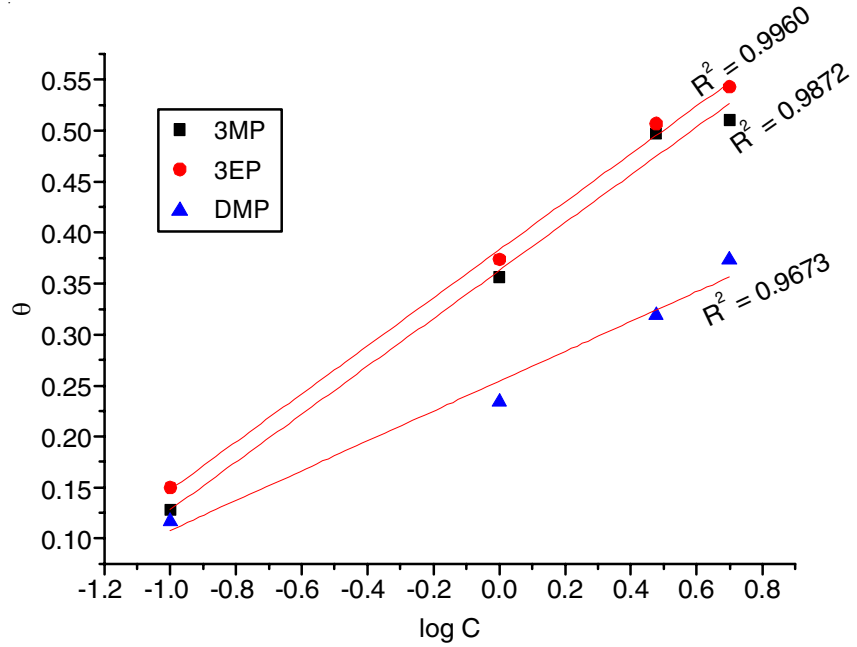

Fig. 13. Temkin Isotherms for the adsorption of inhibitors in $1 \mathrm{~N} \mathrm{HCl}$ solution

negative values of $\Delta \mathrm{G}_{\mathrm{ads}}$ indicate that the adsorption process is spontaneous. The adsorption of piperidine molecules on the metal surface follows Temkin adsorption isotherms. The low values of $\Delta \mathrm{H}^{\#}$ indicate the physical adsorption.

\section{REFERENCES}

1. F. Ovari, L. Tomcsanyi and T. Turmezey, Electrochim. Acta, 33, 323 (1988);

https://doi.org/10.1016/0013-4686(88)85023-0.

2. L. Tomcsányi, K. Varga, I. Bartik, H. Horányi and E. Maleczki, Electrochim. Acta, 34, 855 (1989);

https://doi.org/10.1016/0013-4686(89)87119-1.

3. S.S. Mahmoud, Port. Electrochim. Acta, 26, 245 (2007); https://doi.org/10.4152/pea.200803245.

4. A. Ilamparithi, S. Ponnuswamy and A. Selvaraj, Int. J. Appl. Nat. Sci., 3, 63 (2014) 
5. S. Sankarapapavinasam, F. Pushpanaden and M.F. Ahmed, Corros. Sci., 32, 193 (1991);

https://doi.org/10.1016/0010-938X(91)90043-O.

6. T. Ravindran and R. Jeyaraman, Indian J. Chem., 31B, 677 (1992)

7. V. Maheshwaran, S. Abdul Basheer, A. Akila, S. Ponnuswamy and M.N. Ponnuswamy, Acta Crystallogr. Sect. E Struct. Rep. Online, 69, 1371 (2013);

https://doi.org/10.1107/S1600536813020382.

8. C.R. Noller and V. Baliah, J. Am. Chem. Soc., 70, 3853 (1948); https://doi.org/10.1021/ja01191a092.

9. S. Ponnuswamy, M. Venkatraj, R. Jeyaraman, M. Sureshkumar, D. Kumaran and M.N. Ponnuswamy, Indian J. Chem., 41B, 614 (2002).

10. R.S. Chaudhary and S. Sharma, Indian J. Chem. Technol., 6, 202 (1999).

11. M. Behpour, S.M. Ghoreishi, A. Gandomi-Niasar, N. Soltani and M. Salavati-Niasari, J. Mater. Sci., 44, 2444 (2009); https://doi.org/10.1007/s10853-009-3309-y.
12. M. Benabdellah, R. Touzani, A. Aouniti, A. Dafali, S. El Kadiri, B. Hammouti and M. Benkaddour, Mater. Chem. Phys., 105, 373 (2007); https://doi.org/10.1016/j.matchemphys.2007.05.001.

13. H. Ma, S. Chen, B. Yin, S. Zhao and X. Liu, Corros. Sci., 45, 867 (2003); https://doi.org/10.1016/S0010-938X(02)00175-0.

14. R. Solmaz, M. Mert, G. Kardas, B. Yazici and M. Erbil, Wuli Huaxue Xuebao, 24, 1185 (2008);

https://doi.org/10.1016/S1872-1508(08)60053-4.

15. V.R. Saliyan and A.V. Adhikari, Corros. Sci., 50, 55 (2008); https://doi.org/10.1016/j.corsci.2006.06.035.

16. K.F. Khaled, K. Babic-Samardzija and N. Hackerman, J. Electrochem., 34, 697 (2004);

https://doi.org/10.1023/B:JACH.0000031160.88906.03. 